\title{
Zarka shakedown modelling of expansive soils subjected to wetting and drying cycles
}

\section{Kai Li, Hossein Nowamooz, Cyrille Chazallon \& Bernard Migault}

To cite this article: Kai Li, Hossein Nowamooz, Cyrille Chazallon \& Bernard Migault (2018) Zarka shakedown modelling of expansive soils subjected to wetting and drying cycles, Geomechanics and Geoengineering, 13:2, 77-87, DOI: 10.1080/17486025.2017.1393199

To link to this article: https://doi.org/10.1080/17486025.2017.1393199

\section{Published online: 27 Oct 2017.}

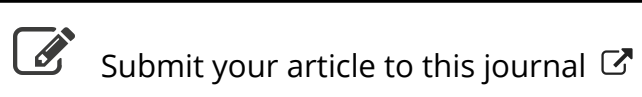

山 Article views: 32

Q View related articles ๘

View Crossmark data \lceil 


\title{
Zarka shakedown modelling of expansive soils subjected to wetting and drying cycles
}

\author{
Kai Lia, ${ }^{\mathrm{a}}$, Hossein Nowamooz ${ }^{\mathrm{b}}$, Cyrille Chazallon ${ }^{\mathrm{b}}$ and Bernard Migault \\ aQingdao Key Laboratory for Geomechanics and Offshore Underground Engineering, Qingdao University of Technology, Qingdao, China; \\ ${ }^{b}$ Group of Civil Engineering in Laboratory of ICUBE, University of Strasbourg, Strasbourg, France
}

\begin{abstract}
Unsaturated expansive soils subjected to wetting and drying cycles result in huge differential settlements of structures built on these materials. The existed models for these materials present large number of parameters that lead to time-consuming procedure to characterise their mechanical behaviour during wetting-drying cycles. In this context, Zarka shakedown theory previously applied to the mechanical loading of granular materials has been used for expansive soils subjected to suction cycles. The parameters of this shakedown-based model were calibrated for two different expansive soils. The comparisons between the experimental results and the calculations for the different tests, demonstrate the capacity of Zarka shakedown theory to simulate the mechanical behaviour of unsaturated expansive soils.
\end{abstract}

\section{ARTICLE HISTORY}

Received 8 May 2016

Accepted 13 October 2017

\section{KEYWORDS}

Expansive soils; mechanical behaviour; constitutive modelling; Zarka shakedown theory

\section{Introduction}

Expansive clayey soils appear in various domains in civil engineering, and their behaviours are influenced by natural environmental fluctuations. When expansive soils are exposed to wetting and drying cycles, this leads to shrinkage or swelling strains which may cause damages in structures. To investigate the mechanical behaviour of expansive soils, several laboratory tests were reported on the effect of drying and wetting cycles on these materials. All these results show that the equilibrium state can be reached at the end of suction cycles, presenting shakedown behaviour of the swelling soils.

Nowamooz and Masrouri (2010a, 2010b) studied the influence of wetting and drying cycles on the mechanical behaviour of loosely and densely compacted bentonite/silt mixtures. In their work, the authors pointed out that the loose samples present a shrinkage strain accumulation while a swelling strain accumulation can be observed for dense samples before reaching a unique equilibrium state at the end of the drying and wetting cycles, regardless of the initial dry density of these expansive soil samples. In other words, the loose and dense samples will achieve a unique final state after a number of suction cycles.

Numerous models were proposed for the complex mechanical behaviour of the swelling soils (Cui et al. 2002, Wheeler et al. 2003, Sun and Sun 2011). Barcelona Expansive Model (BExM) developed by
Gens and Alonso (1992) andAlonso et al. (1999), can be mentioned as the most accepted theoretical reference. This model is able to express the dependency of strain on stress-suction path, accumulation of expansion strain or compression strain during suction cycles, strain fatigue during wetting-drying cycles. However, a large number of parameters such as the coupling functions for micro- and macro-structural strains, are introduced in this model. The determination of these parameters requires several suction-controlled oedometer tests which lead to a time-consuming procedure to characterise their mechanical behaviours.

Simplified shakedown theory was initially developed by Zarka and Casier (1979), (1990)) for the kinematic hardening materials such as metals. The plastic strains at shakedown states were calculated based on Melan's static theorem by introducing the transformed internal variables. Sharp and Booker (1984) for the first time applied the shakedown theory to model the behaviour of unbound granular materials and defined the shakedown load as a key design load for engineering practice. A shakedown model based on Zarka theory with a non-associated flow rule have developed by Habiballah and Chazallon (2005), Allou et al. (2007) and Chazallon et al. (2009a, 2009b), for the unbound granular materials to determine the accumulation of plastic strains during periodical traffic loadings.

In this context, this paper presents a shakedownbased model to improve the modelling of expansive soils and simulate the behaviour of unsaturated 
expansive soils subjected to wetting and drying cycles under different vertical pressures. The necessary parameters in the proposed model are calibrated by the suction-controlled test results carried out on different expansive soils. Finally, the model is validated for the intermediate samples to compare the experimental results with model predictions. These comparisons show that the shakedown-based model is able to replace step-by-step method to estimate accumulated plastic strains during suction cycles and save the calculation time for large cycle numbers.

\section{The simplified method of zarka for mechanical loadings}

Based on the associated elasto-plastic flow rule and the linear kinematic hardening, Zarka introduces a series of transformed internal variables to describe the mechanical system and constructs a local geometry in the transformed internal parameter plane to estimate the limit equilibrium state and the corresponding plastic components.

In the case of one dimensional elastic-plastic problem, the elastic behaviour of the material can be supposed linear, independent of temperature. Thus, the mechanical problem can be solved as follows:

$$
\varepsilon(t)=\frac{1}{E} \cdot \sigma(t)+\varepsilon^{p}(t)+\varepsilon^{I}(t)
$$

where $\sigma(t)$ is the applied stress, $\varepsilon(t)$ the total strain, $\varepsilon^{p}(t)$ the plastic strain, $E$ the elastic modulus, and $\varepsilon^{I}(t)$ the initial strain (taken equal to 0 in this study). The yield surface equation with a linear kinematic hardening can be written as:

$$
f=\left|\sigma-y_{\alpha}\right|-\sigma_{\alpha}
$$

where, $\sigma_{\alpha}$ is the yield stress and $y_{\alpha}$ the kinematic hardening variable is related to the plastic strain,

$$
y_{\alpha}=h \cdot \varepsilon^{p}
$$

where, $h$ is the kinematic hardening modulus.

When $f=0$, the yield surface equation can be written as:

$$
\sigma=\sigma_{\alpha}+y_{\alpha}
$$

In this stress plane, the normality law of plasticity can be written with the Moreau's notation (Moreau 1971):

$$
\dot{\varepsilon}^{p} \in \partial \phi_{C\left(y_{\alpha}\right)}(\sigma) \text { with } \sigma \in C\left(y_{\alpha}\right)
$$

$\partial \phi_{C\left(y_{\alpha}\right)}(\sigma)$ is the subdifferential to the convex $C\left(y_{\alpha}\right)$, where the plastic strain rate is an external normal to the convex $C\left(y_{\alpha}\right)$ (see Figure 1(a)).

We present the convex in the transformed internal parameter $y_{\alpha}$ plane (see Figure 1(b)) and rewrite the yield surface when $f=0, y_{\alpha}$ can be expressed in terms of the given applied stress,

$$
y_{\alpha}=\sigma-\sigma_{\alpha}
$$

Here, $y_{\alpha}$ represents the transformed internal parameter and this equation indicates that the yield surface centred in applied stress $\sigma$ with a radius of $\sigma_{\alpha}$, translates in transformed internal parameter $y_{\alpha}$ plane. In this transformed internal parameter $y_{\alpha}$ plane, the normality law of plasticity becomes:

$$
\dot{\varepsilon}^{p} \in-\partial \phi_{C(\alpha)}\left(y_{\alpha}\right) \text { with } y_{\alpha} \in C(\sigma)
$$

$-\partial \phi_{C(\sigma)}\left(y_{\alpha}\right)$ is the sub-differential to the convex $C(\sigma)$, where the plastic strain rate is an internal normal to the plasticity convex (see Figure 1(c)).

Two cases exist according to the loading amplitude in the transformed internal parameter plane:

- Elastic shakedown. The extreme positions of the convex centred in $\sigma_{\min }$ and $\sigma_{\max }$ have a common part and elastic shakedown will occur (Figure 1(d)). In this case, the response of material becomes purely elastic after a certain number of cycles and plastic strain fields tend towards constant fields depending on the initial state of the material. For this, the accumulated plastic strains during cyclic loadings can be computed by the following equation,

$$
\Delta \varepsilon^{p}=\frac{\Delta\left(\sigma-\sigma_{\alpha}\right)}{h}
$$

where, $\sigma$ is the applied stress.

- Plastic shakedown. When the loading amplitude is large, the extreme positions of the convex have no common part and in this case, plastic shakedown occurs (Figure 1(e)). For plastic shakedown, the response of material becomes periodic during cycles with a periodic plastic strain field where a closed elastic-plastic loop is obtained, treated as a steady state with no additional accumulation of plastic deformation. In the case of plastic shakedown, the maximum plastic strain and the minimum plastic strain between $\sigma_{\min }$ and $\sigma_{\max }$ can be defined in the transformed internal parameter plane:

$$
\begin{gathered}
\varepsilon_{\max }^{p}=\frac{1}{h} \cdot\left(y_{\text {moy }}+\frac{1}{2} \cdot \Delta y_{\alpha}\right) \\
\varepsilon_{\min }^{p}=\frac{1}{h} \cdot\left(y_{\text {moy }}-\frac{1}{2} \cdot \Delta y_{\alpha}\right)
\end{gathered}
$$

where, $y_{\text {moy }}$ presented in Figure $1(\mathrm{e})$ is equal to $\left(\sigma_{\max }+\sigma_{\min }\right) / 2$. 
a)

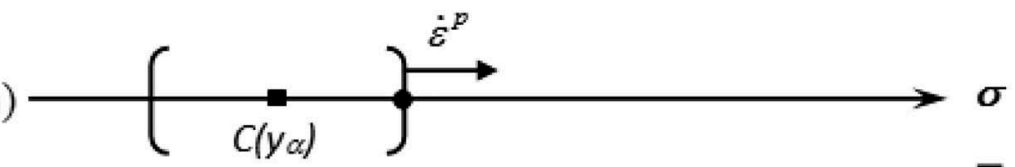

From the stress plane to the transformed internal parameter plane
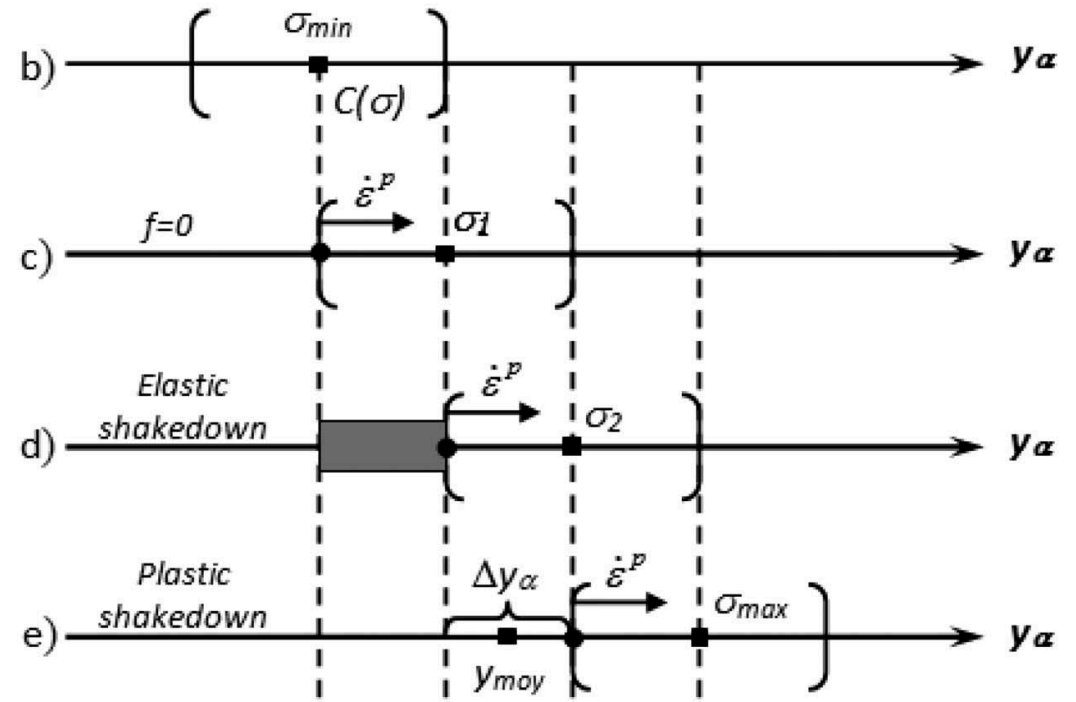

Figure 1. Transformed internal parameter plane for elastic shakedown and plastic shakedown.

It should be added that collapse does not occur for kinematic hardening materials during the cyclic loadings for the elastic and plastic shakedown theory. Although Zarka simplified method cannot predict the collapse of material, it provides sufficient estimations of the deformation and the displacement at the shakedown stage.

\section{Shakedown-based model for hydro- mechanical loadings}

The purpose of this section is to present a simplified shakedown-based model to simulate the mechanical behaviour of unsaturated expansive soils during the successive wetting and drying cycles.

It is generally accepted that a unique plane (net mean stress-suction) is sufficient to characterise the mechanical behaviour of unsaturated soils.

- Net mean stress is the excess of the mean stress over air pressure, named as $p$;

- Suction is the excess of the air pressure over water pressure, named as $s$.

In this study, a rectangular yield surface representing the elastic domain shows in $p-s$ plane in Figure 2. The equations of the different boundaries can be given by:

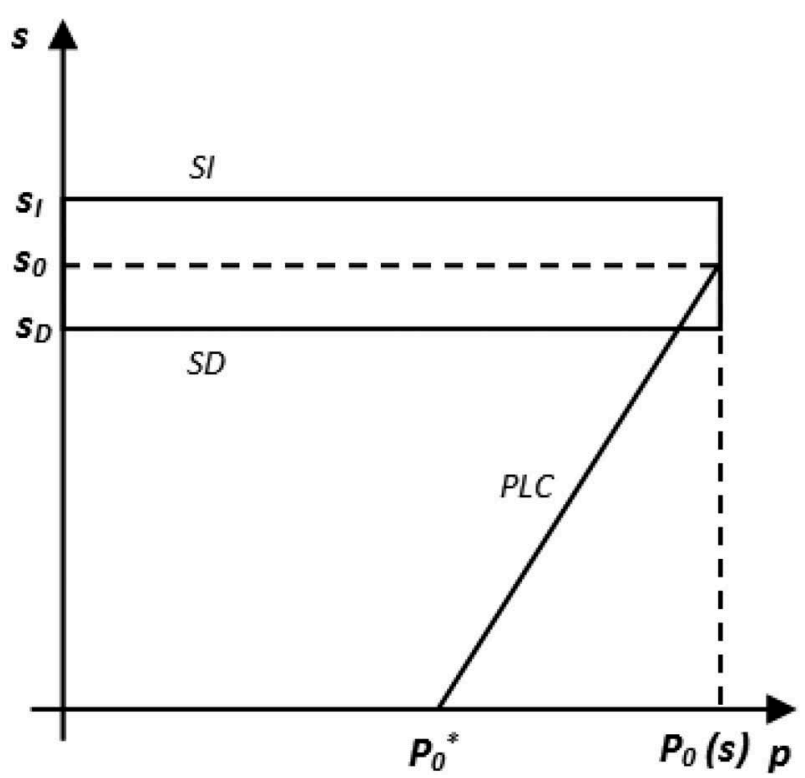

Figure 2. PLC, $s_{1}$ and $s_{D}$ yield surfaces in the plane of suctionpreconsolidation stress.

$$
\begin{aligned}
& s=s_{I} \\
& s=s_{D} \\
& p=p_{0}
\end{aligned}
$$


where, $s_{I}$ is the Suction Increase limit, $s_{D}$ is the Suction Decrease limit and $p_{0}$ is the Pre-consolidation Stress.

In this work, we take into account the following hypotheses for the yield surfaces:

1) the width of the elastic domain is small and is not changing with suction cycles.

The suction variation within the rectangular will result in the elastic volumetric strain:

$$
d \varepsilon_{v s}^{e}=\frac{\kappa_{s}}{v} \cdot \frac{d s}{s}
$$

where $v$ is the specific volume, equal to $1+e_{0}$, where $e_{0}$ is the initial void ratio of the sample.

And if the boundaries $s=s_{I}$ and $s=s_{D}$ are activated, the following total and plastic volumetric strain will be generated,

$$
\begin{gathered}
d \varepsilon_{v s}=\frac{\lambda_{s}}{v} \cdot \frac{d s_{i}}{s_{i}} \\
d \varepsilon_{v s}^{p}=\frac{\lambda_{s}-\kappa_{s}}{v} \cdot \frac{d s_{i}}{s_{i}}
\end{gathered}
$$

in which, $\kappa_{s}$ and $\lambda_{s}$ are elastic stiffness index and elastoplastic stiffness index for suction variation, respectively. In short, $s_{i}$ represents the activated boundary $s_{I}$ when suction increases, while $s_{i}$ represents the activated boundary $s_{D}$ when suction decreases, respectively.

2 ) the length of the rectangular depends on the suction level.

Based on this hypothesis, we define a Pseudo Loading Collapse (PLC) curve, with a linear relation between the pre-consolidation stress and suction level. This relation can be given by:

$$
p_{0}(s)=A \cdot s+B
$$

where, $A$ and $B$ can be determined by the isotropic compression tests at different suctions. This linear proposition is only used to guarantee the shakedown behaviour of expansive soils during wetting and drying cycles. To predict the accurate elasto-plastic behaviour of expansive soils due to mechanical loading, nonlinear relation of loading collapse can be added, such as the Barcelona Basic model (Alonso et al. 1990).

Parameter $A$, controlling the slope of PLC curves, is constant during suction cycles since these curves are only activated along $p$-axis.

Parameter $B$ can be given by:

$$
B=p_{0}^{*}\left(\gamma_{d}\right)
$$

where, $p_{0}{ }^{*}\left(\gamma_{d}\right)$ is the pre-consolidation stress for saturated state, changing with the initial state (loose or dense state).

The increase of the net mean stress within the rectangular will generate the elastic volumetric strain:

$$
d \varepsilon_{v p}^{e}=\frac{\kappa}{v} \cdot \frac{d p}{p}
$$

and if the boundary $p=p_{0}(\mathrm{~s})$ is reached, the following total and plastic volumetric strain will be given by,

$$
\begin{gathered}
d \varepsilon_{v p}=\frac{\lambda(s)}{v} \cdot \frac{d p_{0}}{p_{0}} \\
d \varepsilon_{v p}^{p}=\frac{\lambda(s)-\kappa}{v} \cdot \frac{d p_{0}}{p_{0}}
\end{gathered}
$$

in which, $\kappa$ and $\lambda(s)$ are elastic stiffness index and elasticplastic stiffness index for loading variation, respectively.

The above simplified model for isotropic stress state is used to the subsequent shakedown modelling, instead of step-by-step calculation of material deformations, although it has a similar formulation as BBM model. To facilitate the shakedown modelling in the transformed internal parameter plane, a simple shape of yield surface (i.e. rectangle) is taken into account in this study and it will be employed in the next section of shakedown modelling.

\subsection{Plastic shakedown during suction cycles}

- Water retention curves during suction cycles. Water retention curve is one of the essential parameters required for hydro-mechanical modelling in unsaturated expansive soils. Figure 3 shows the conceptual evolution of water retention curve during suction cycles.

- In this figure, there is an evident hysteresis phenomenon before suction cycles. The hysteresis becomes smaller with the following suction cycles. However, it cannot be completely eliminated even

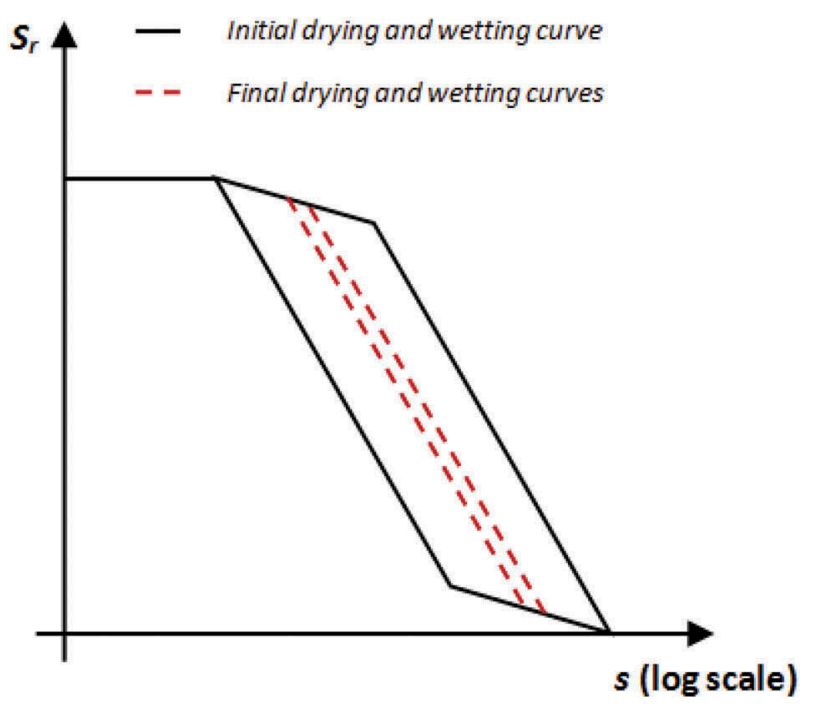

Figure 3. Evolution of the water retention curves with suction cycles. 
though the equilibrium state is reached after several suction cycles. This hydraulic behaviour indicates that plastic shakedown occurs during suction cycles. In other words, plastic shakedown should be used to model mechanical behaviour of expansive soils when wetting and drying cycles are applied.

- Plastic shakedown modelling. The proposed yield surface with a kinematic hardening for suction variations can be written as:

$$
f=\left|s-y_{\alpha}\right|-s_{\alpha}
$$

where, $s_{\alpha}$ is the threshold value of elastic limit for suction variation.

The kinematic hardening variable $y_{\alpha}$ can be related to the plastic strain,

$$
y_{\alpha}=h \cdot \varepsilon^{p}
$$

where, $h$ is the kinematic hardening modulus.

To perform shakedown modelling, the proposed yield surface is presented in the transformed internal parameter $y_{\alpha}$, as well as the pre-consolidation stress $p$ plane (see Figure 4). In this (transformed internal parameter - pre-consolidation stress) plane, the convex which characterises the behaviour of the soil sample translates between the minimum suction $s_{\min }$ position and the maximum suction $s_{\max }$ position during the wetting and drying cycles.

If the extreme positions of the two convexes have no common part on the transformed internal parameter axis, plastic shakedown occurs. Therefore, the variation of the volumetric plastic deformation $\Delta \varepsilon_{v s}^{p}$ during suction cycles can be computed by:

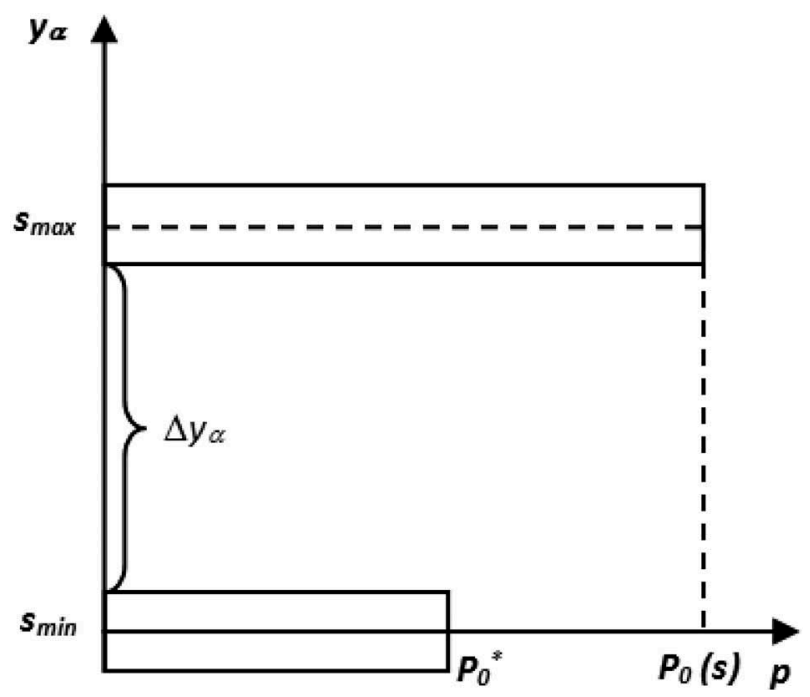

Figure 4. Transformed internal parameter-preconsolidation stress plane for the plastic shakedown.

$$
\Delta \varepsilon_{v s}^{p}=\frac{1}{h} \cdot \Delta y_{\alpha}
$$

where, $h$ is the kinematic hardening modulus, a constant material parameter at the given net mean stress. Additionally, $y_{\alpha}$ can be determined in the transformed internal parameter plane when the minimum suction and the maximum suction are given.

\subsection{Elastic behaviour at the equilibrium state}

After several wetting and drying cycles, unsaturated expansive soil is able to reach an equilibrium state where no additional plastic strain accumulation is observed. Figure 5 presents the volumetric change in the strain and suction plane. Because there are few experimental points measured at the equilibrium state in terms of the current laboratory tests, the hysteresis phenomenon cannot be expressed exactly. Consequently, a linear variation of the elastic strain with the suction is supposed at the equilibrium state.

It can be written as:

$$
\Delta \varepsilon_{v s}^{e}=\frac{\kappa_{s}}{v} \cdot \frac{\Delta s}{s}
$$

where, $\kappa_{s}$ is the elastic stiffness index for suction variation.

\subsection{Coupling between suction cycles and mechanical behaviour}

Gens and Alonso (1992) identified that the swelling plastic strain during wetting and drying cycles under a vertical pressure results in a macro-structural soft-

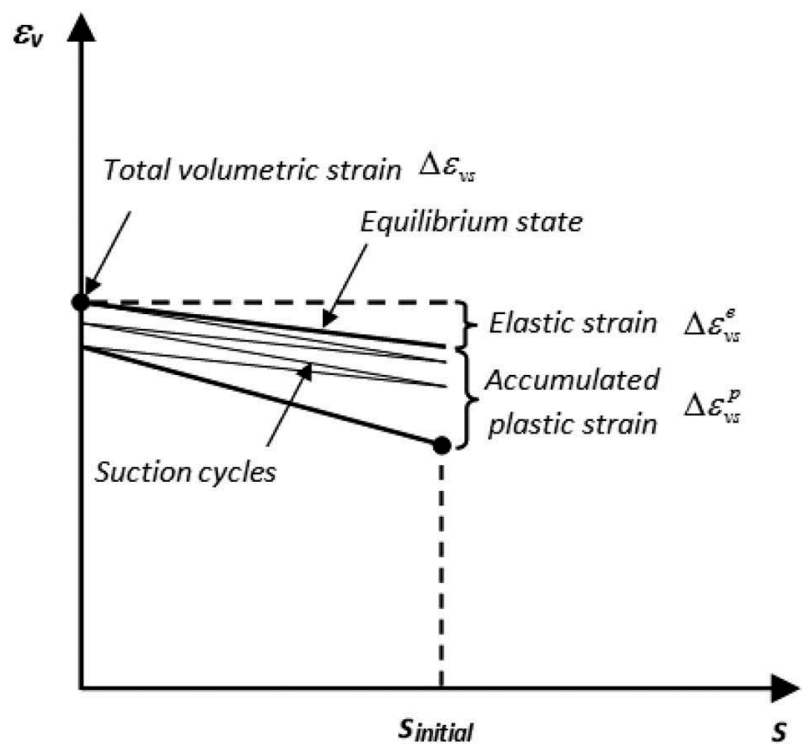

Figure 5. Variation of the volumetric strain with suction during wetting and drying cycles. 
ening behaviour of expansive soils, causing a left movement of the initial loading collapse yield surface (named PLC in this study) presented in Figure 6. On the contrary, the occurrence of shrinkage strain produced by suction cycles results in an outward movement of loading collapse yield surface to the right of the initial PLC yield surface, associated with a macrostructural hardening behaviour.

Experimental evidence illustrates that the pre-consolidation stress strongly depends on the macro-structural plastic strain during wetting and drying cycles. For the sake of simplicity, we suppose that the increase of pre-consolidation stress is linear with the variation of volumetric plastic strain produced by suction cycles, the same equation as BBM (or BExM):

$$
\frac{d p_{0}^{*}}{p_{0}^{*}}=\frac{1+e_{0}}{\lambda(0)-\kappa} \cdot d \varepsilon_{v s}^{p}
$$

where, $\lambda(0)$ is stiffness parameters for changes in net mean stress at the saturated states and $\kappa$ is elastic stiffness parameter for changes in net mean stress.

The volumetric plastic strain during wetting and drying cycles $\left(\varepsilon_{v s}^{p}\right)$, predicted by the proposed shakedown model, is used to find the pre-consolidation stress $\left(p_{0}^{*}\right)$ for the saturated state based on the Equation 26. Subsequently, this saturated pre-consolidation stress $\left(p_{0}^{*}\right)$ is employed in Equation 17 to determine the value of pre-consolidation stress $p_{0}(s)$ and the final position of the PLC yield surface. Finally, the coupling law between the suction cycles and subsequent mechanical behaviour is developed.

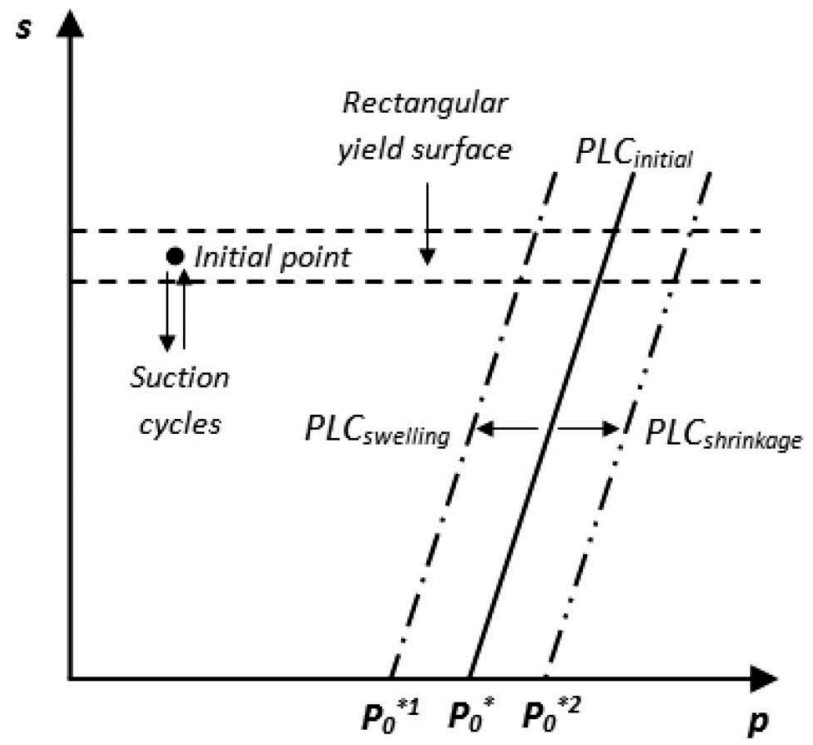

Figure 6. Evolution of the initial yield surface with suction cycles for expansive soils in (suction-preconsolidation stress) plane.

\section{Calibration of the parameters for the shakedown-based model}

\subsection{Laboratory test results}

The capacity of our modified shakedown concept to model the mechanical behaviour of the swelling soils is initially investigated for the experimental results published by Alonso et al. (2005). Three cyclic wetting and drying cycles between 130 and $4 \mathrm{MPa}$ under constant net vertical stress of 98,196 and $396 \mathrm{kPa}$ were performed on a compacted mixture of bentonite-sand with an initial dry density of $1.5 \mathrm{Mg} \cdot \mathrm{m}^{-3}$. The differences between two successive wetting and drying paths become smaller as the number of cycles increases and eventually shrinkage strain is accumulated. Clearly, the soil tends towards an elastic state at the end of suction cycles.

\subsection{Parameter calibration procedures}

- Since the width of two elastic boundaries $s_{I}$ and $s_{D}$ is very small, taken equal to zero for the sake of simplification. From the suction cycle tests, suction variation is given and $y_{\alpha}$ is able to be deduced based on Zarka method, the same as Equation 6.

- Because wetting and drying tests define the strain variations with suction cycles, it gives accumulated plastic deformation $\Delta \varepsilon_{v s}^{p}$ during suction cycles.

- When we know the accumulated plastic deformation $\Delta \varepsilon_{v s}^{p}$, as well as the transformed internal parameter $y_{\alpha}$ at a given net mean stress, the hardening module $h$ can be deduced according to Equation 24.

- The elastic stiffness index for suction variation $\kappa_{s}$ can be estimated from the last wetting and drying cycle at the equilibrium state, considered to be constant in this study.

- Table 1 summarises the calibrated parameters based on the test results for the proposed model with Zarka plastic shakedown concept.

\subsection{Evolution law of model parameters}

Because of the volumetric shrinkage strains during the suction cycles, a positive sign was used for the $h$ values to show the hardening phenomenon. The inverse of

Table 1. Calibration of required parameters of shakedownbased model for the studied material of Alonso et al. (2005).

\begin{tabular}{lccc}
\hline Net mean stress $(\mathrm{kPa})$ & 98 & 196 & 396 \\
Hardening modulus $h(\mathrm{MPa})$ & 3405 & 2800 & 1800 \\
Elastic region limit $s_{r}-s_{D}(\mathrm{MPa})$ & 0 & 0 & 0 \\
Elastic stiffness index for suction variation $\kappa_{s}$ & 0.04 & 0.04 & 0.04 \\
\hline
\end{tabular}




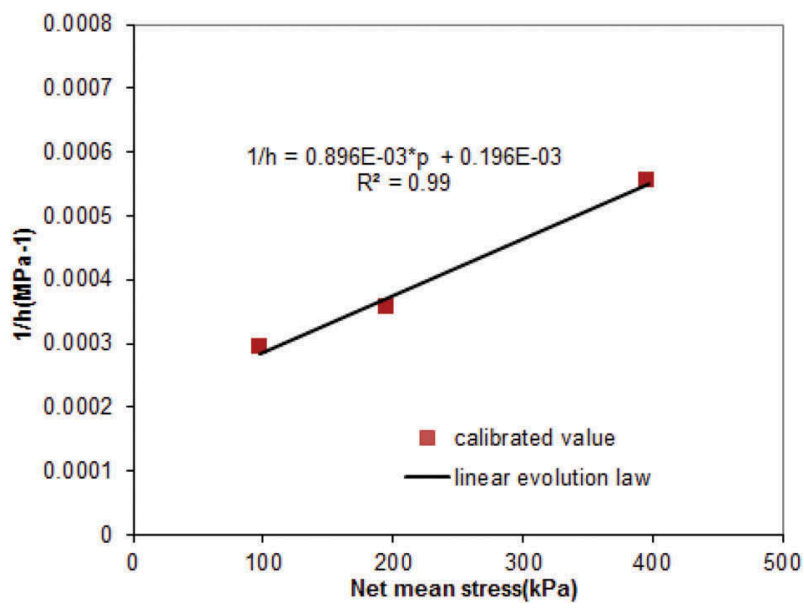

Figure 7. Evolution law of the inverse of the hardening modulus with net mean stress for the samples studied by Alonso et al. (2005).

hardening modulus $(1 / h)$ varies linearly with net mean stress. Figure 7 illustrates the evolution of hardening parameter with different net mean stress. The larger the applied vertical pressure, the larger the inverse of the hardening modulus $(1 / h)$. In other words, the accumulated plastic deformation increases with an increase of the net mean stress. Finally, we can propose the following linear expression between the inverse of the hardening modulus $(1 / h)$ and the net mean stress $(p)$,

$$
1 / h=C \cdot p+D
$$

where, $C$ and $D$ are material constants. Table 2 shows the variation of these parameters for this studied material.

The comparison between test results and the model estimation at a given net mean stress $(196 \mathrm{kPa})$ is
Table 2. Variation of parameter $C$ and $D$ for the studied material of Alonso et al. (2005).

\begin{tabular}{lcc}
\hline Parameter & $C\left(\mathrm{MPa}^{-2}\right)$ & $D\left(\mathrm{MPa}^{-1}\right)$ \\
\hline Value & 0.896 & $0.196 \mathrm{E}-03$ \\
\hline
\end{tabular}

presented in Figure 8. The small relative error of $1.9 \%$ shows that the shakedown-based model is able to reproduce the accumulated plastic strains during the suction cycles at constant net mean stress.

\section{Validation of the shakedown-based model}

Nowamooz and Masrouri (2008) and Nowamooz et al. (2013) performed the experiments on an artificially prepared mixture of $40 \%$ silt and $60 \%$ bentonite. The soil samples were compacted with the same initial water content $w=15 \%$ and three different initial dry densities were $\gamma_{d}=1.27,1.48$ and $1.55 \mathrm{Mg} \cdot \mathrm{m}^{-3}$, corresponding to loose (L), intermediate (I) and dense (D) state, respectively.

To determine the required parameters of the proposed shakedown model, we apply the same calibration procedure as the details presented in the Section 4, using the test results with wetting and drying cycles between 8 and $0 \mathrm{MPa}$ under three constant net mean stresses: 15,30 and $60 \mathrm{kPa}$.

The parameters were calibrated for the loose and dense materials. Tables 3 and 4 summarise the required parameters: hardening modulus $(h)$, elastic stiffness index for suction variation $\left(\kappa_{s}\right)$ and elastic region limit $\left(s_{I}-s_{D}\right)$ of shakedown-based model for loose and dense samples, respectively. For the modelling, we

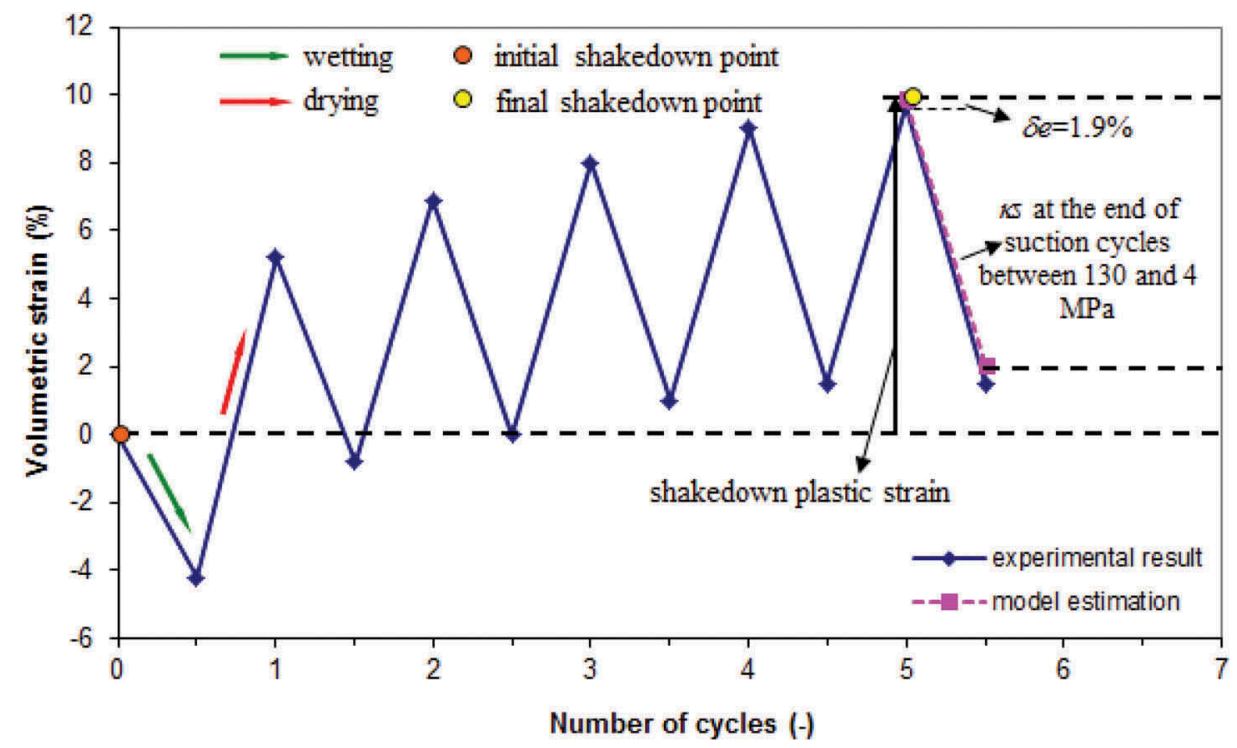

Figure 8. Comparison of model estimation with test results reported by Alonso et al. (2005) at the net mean stress of $196 \mathrm{kPa}$. 
Table 3. Required parameters of shakedown-based model for loose sample studied by Nowamooz and Masrouri (2008).

\begin{tabular}{lccc}
\hline Net mean stress $(\mathrm{kPa})$ & 15 & 30 & 60 \\
Hardening modulus $h(\mathrm{MPa})$ & 126 & 79 & 60 \\
Elastic region limit $s_{\perp} s_{D}(\mathrm{MPa})$ & 0 & 0 & 0 \\
Elastic stiffness index for suction variation $\kappa_{s}$ & 0.02 & 0.02 & 0.02 \\
\hline
\end{tabular}

Table 4. Required parameters of shakedown-based model for dense sample.

\begin{tabular}{lccc} 
Net mean stress $(\mathrm{kPa})$ & 98 & 196 & 396 \\
Hardening modulus $h(\mathrm{MPa})$ & -125 & -163 & -540 \\
Elastic region limit $s_{\text {I_ }} S_{D}(\mathrm{MPa})$ & 0 & 0 & 0 \\
Elastic stiffness index for suction variation $\kappa_{s}$ & 0.04 & 0.04 & 0.04 \\
\hline
\end{tabular}

assume a very small elastic domain where $\left(s_{I}-s_{D}\right)$ are equal to zero.

Figure 9 shows the evolution law of the inverse of the hardening modulus $(1 / h)$ with the net mean stress $(p)$ for loose and dense samples, respectively. The inverse of the hardening modulus $(1 / h)$ and net mean stress $(p)$ can be defined with the same linear expression of the Equation 27. Table 5 shows the variation of these parameters for the loose and dense samples.

Figures 10 and 11 present the model calibration compared with experimental results at different net mean stress for the loose and dense samples, respectively. It can be observed that the wetting and drying cycles generate shrinkage strain accumulation for the loose samples and swelling strain accumulation for dense samples. The model estimations show that the equilibrium state reached for both loose and dense materials where they exhibit a reversible behaviour at the end of drying and wetting cycles,
Table 5. Variation of parameter $C$ and $D$ for loose and dense sample studied by Nowamooz and Masrouri (2008).

\begin{tabular}{lcr}
\hline Parameter & $C\left(\mathrm{MPa}^{-2}\right)$ & $D\left(\mathrm{MPa}^{-1}\right)$ \\
\hline Loose $\left(\gamma_{\mathrm{d}}=1.27 \mathrm{mg} \cdot \mathrm{m}^{-3}\right)$ & 0.188 & $0.589 \mathrm{E}-02$ \\
Dense $\left(\gamma_{\mathrm{d}}=1.55 \mathrm{mg} \cdot \mathrm{m}^{-3}\right)$ & 0.138 & $-0.101 \mathrm{E}-03$ \\
\hline
\end{tabular}

and the model calculations produce a good agreement with small relative errors.

The validation of the model is carried out with the tests of the intermediate samples. The model parameter for the intermediate samples $\left(s_{I}-s_{D}\right)$ is taken equal to zero, the same as the loose and dense states presented in Tables 3 and 4 . The parameters $C$ and $D$ for the intermediate samples are interpolated based on the previous estimated values of the loose and dense samples in Table 5. As to the parameter elastic stiffness index for suction variation $\left(\kappa_{s}\right)$ for intermediate sample also can be interpolated by the values of the loose and dense samples. These values for the intermediate samples are presented in Table 6. Additionally, the extrapolated line of the inverse of the hardening modulus $(1 / h)$ for intermediate samples is illustrated in Figure 9.

Figure 12 represents the comparison of test results with the model predictions for intermediate soil at different net mean stress. For intermediate soils, the initial state is closer to the reversible line which need less suction cycles to obtain the equilibrium state. The relative error varies between $5.1 \%$ and $8 \%$ confirming the capacity of the model to predict the accumulated plastic strains for another initial state.

Table 7 presents the parameters $(A, B, \lambda(0)$ and $\kappa)$ based on Equations 17 and 26 to illustrate the PLC

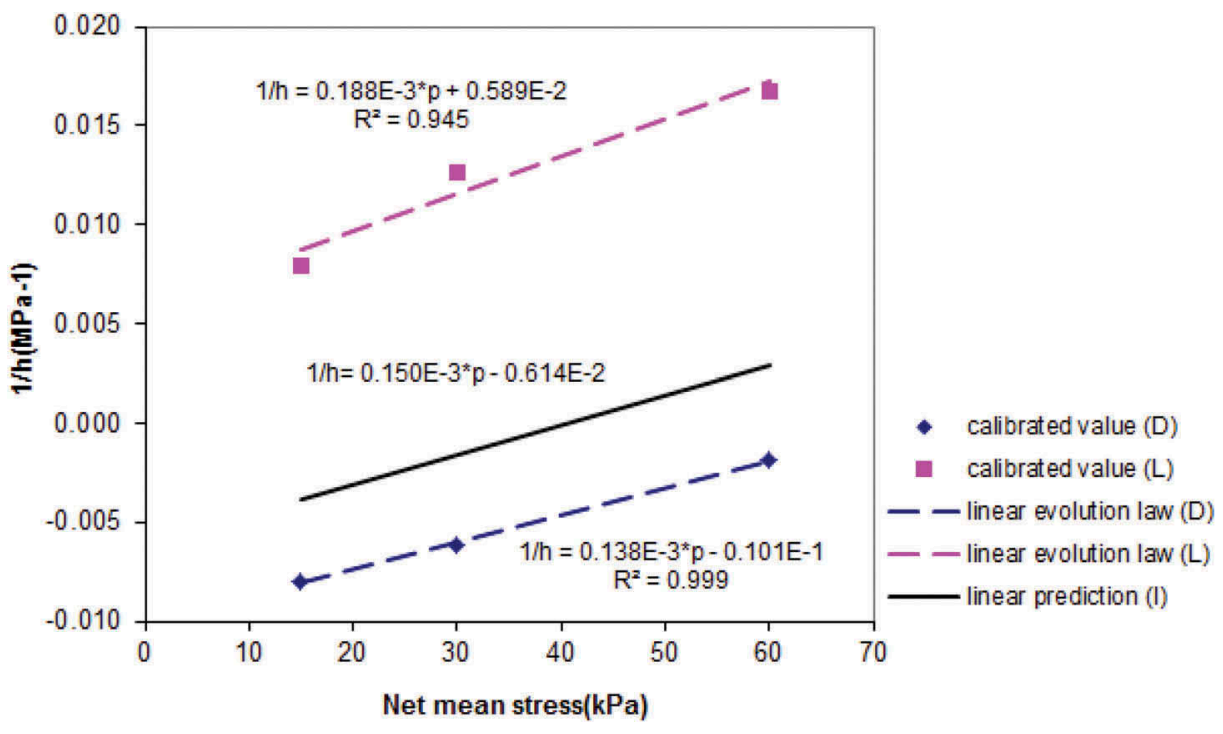

Figure 9. Evolution law of the inverse of the hardening modulus with net mean stress for the different samples studied by Nowamooz and Masrouri (2008). 


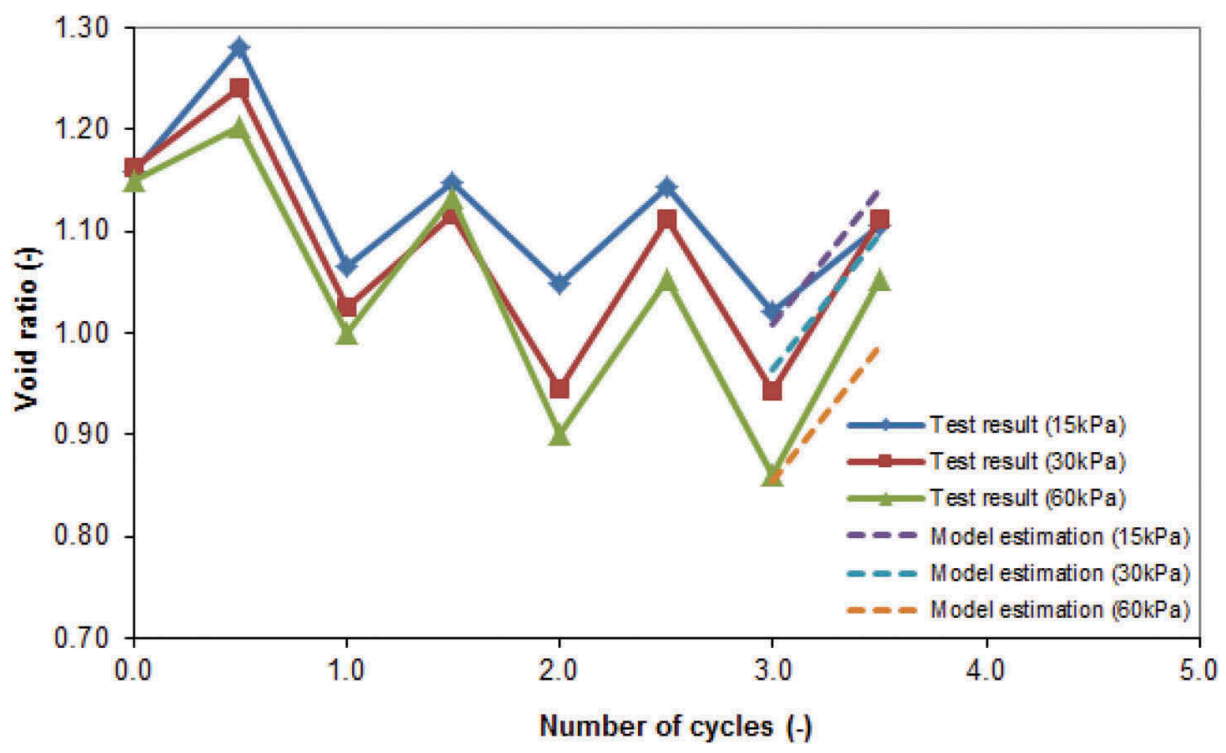

Figure 10. Comparison of test results with model estimations for the loose samples at the different net mean stresses.

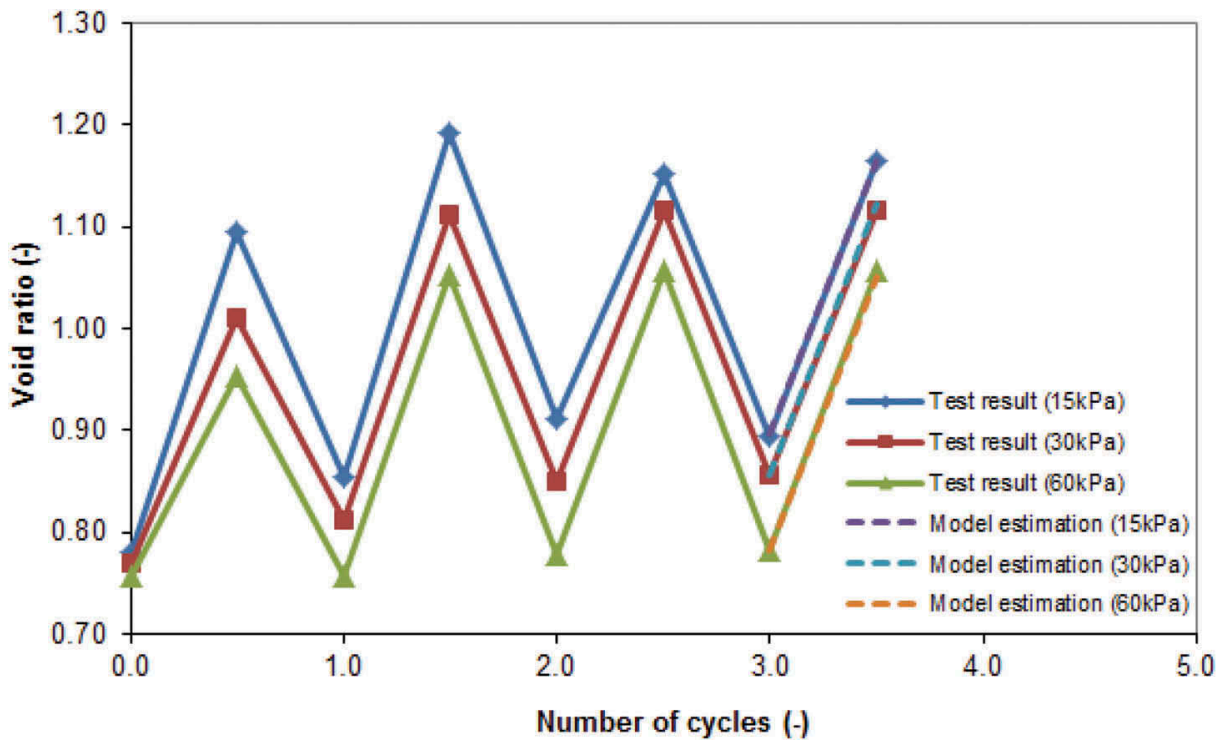

Figure 11. Comparison of test results with model estimations for the dense samples at the different net mean stresses.

Table 6. Variation of parameter $C, D$ and $\kappa_{s}$ for the intermediate initial states.

\begin{tabular}{llcc}
\hline Parameter & $C\left(\mathrm{MPa}^{-2}\right)$ & $D\left(\mathrm{MPa}^{-1}\right)$ & $\kappa_{s}$ \\
\hline Intermediate $\left(\gamma_{\mathrm{d}}=1.48 \mathrm{mg} \cdot \mathrm{m}^{-3}\right)$ & 0.150 & $-0.614 \mathrm{E}-02$ & 0.03 \\
\hline
\end{tabular}

curve before suction cycles for the intermediate initial dry density. Figure 13 shows the initial and final PLC yield surfaces after suction cycles between 8 and $0 \mathrm{MPa}$ for the intermediate state. To show the swelling strain accumulation as well as the softening behaviour for the intermediate state, the PLC yield surface at the beginning of the suction cycles is also presented in this figure.
Here, we emphasise that for shakedown modelling of unsaturated expansive soils, the parameters $(1 / h)$ depending on $C$ and $D$ parameters, $\left(\kappa_{s}\right)$ and $\left(s_{I}-s_{D}\right)$ are sufficient to determine the final asymptotic state. It is important to determine the final equilibrium state, because it presents the mechanical behaviour of unsaturated expansive soil subjected to several suction cycles.

\section{Conclusion}

In this paper, we have used a linear kinematic hardening model to characterise the mechanical behaviour of the expansive soils. The plastic shakedown can be 


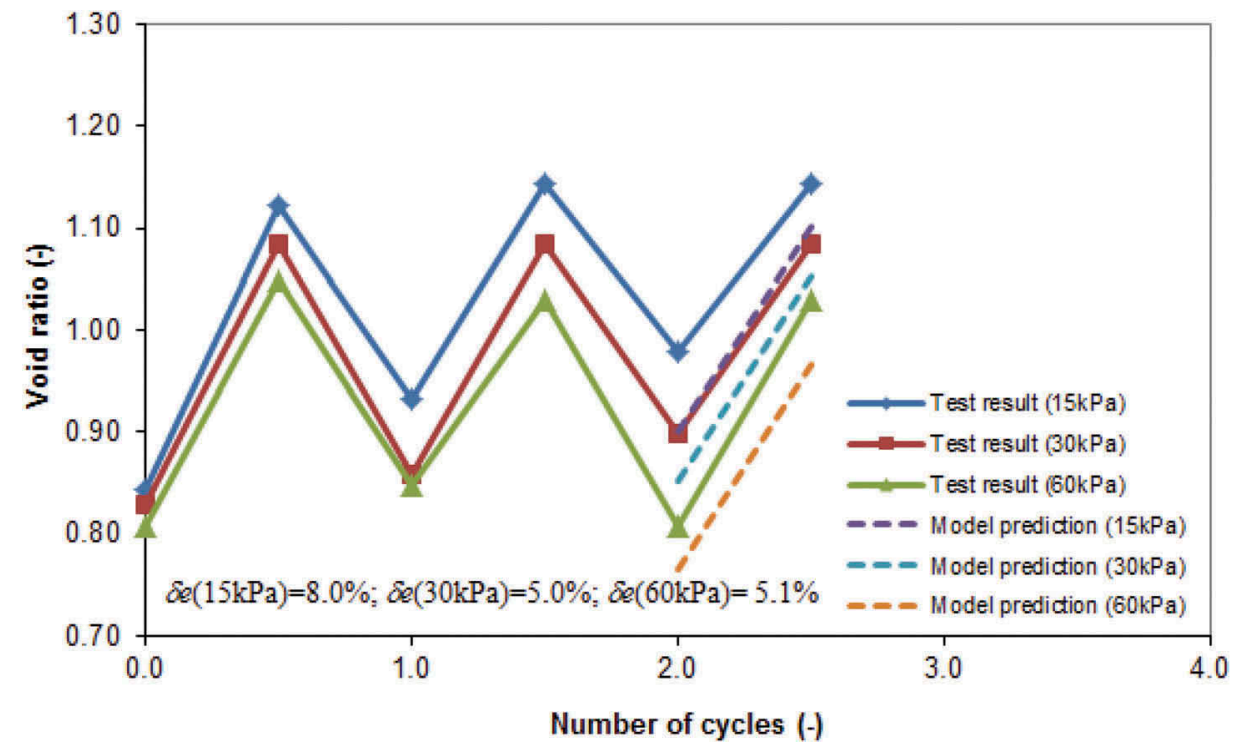

Figure 12. Comparison of test results with model predictions for the intermediate samples at the different net mean stresses.

Table 7. Parameters of the coupling model between suction cycles and mechanical behaviour for the intermediate sample studied by Nowamooz et al. (2013).

\begin{tabular}{lcccc}
\hline Parameter & $A$ & $B(\mathrm{kPa})$ & $\lambda(0)$ & $\kappa$ \\
\hline Intermediate $\left(\gamma_{\mathrm{d}}=1.48 \mathrm{mg} \cdot \mathrm{m}^{-3}\right)$ & 0.0676 & 190 & 0.22 & 0.02 \\
\hline
\end{tabular}

investigated in the transformed internal parameter plane with a rectangular shape for the yield surface. The plastic shakedown happens during the suction cycles when there is no intersection between two extreme positions of the convex.
Parameter calibrations for shakedown-based model requires to determine four parameters: parameter $C$ and $D$ for hardening parameter $(1 / h)$, elastic stiffness index for change in suction $\left(\kappa_{s}\right)$ and elastic region limit $\left(s_{I^{-}} \mathcal{S}_{D}\right)$, from suction cycles tests at a constant net mean stress. The translation of the PLC curve can be also illustrated based on the coupling law between the suction cycles and the mechanical behaviour.

Calibrations of model parameters with laboratory tests have been performed with loose and dense samples. The prediction of the intermediate state is carried

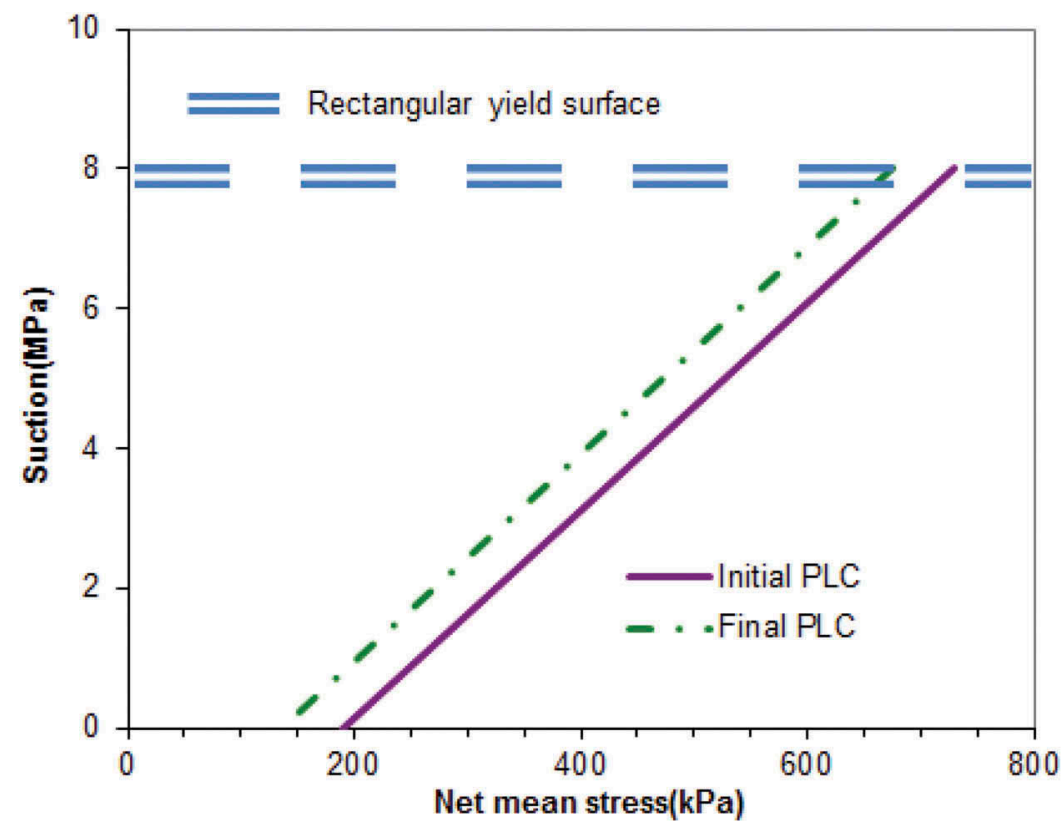

Figure 13. Initial and final PLC curves during suction cycles between 8 and $0 \mathrm{MPa}$ for the intermediate sample studied by Nowamooz et al. (2013). 
out and good results have been obtained. The proposed model is able to take into account the mechanical behaviour of unsaturated expansive soils with a wide range of density.

Our future development for the material behaviour, will deal with an extension of Zarkashakedown theory with a combined hardening plasticity (kinematic hardening and isotropic hardening), to improve our proposed shakedown-based model for the behaviour of dense swelling soils when elastic shakedown occurs. Then, the integration of our model in a finite element code to analyse the settlement of a structure subjected to wetting and drying cycles will be carried out. Cast $3 \mathrm{M}$ has already been used for shakedown analysis of low traffic pavements (Habiballah and Chazallon (2005), Allou et al. (2007) and Chazallon et al. (2009a, 2009b)) subjected to traffic loading, the same framework also can be used to model the influence of wetting-drying cycles on the settlement of the swelling soils, where the same concept of shakedown is able to be employed in the deviatoric stress plane for the first and the suction axis for the second.

\section{Acknowledgements}

This work is financially supported by the project of Natural Science Foundation of Shandong Province (Grant No: ZR2016AB18) and the program of China Scholarship Council (CSC No.: 2011008046).

\section{Disclosure statement}

No potential conflict of interest was reported by the authors.

\section{Funding}

This work is financially supported by the project of Natural Science Foundation of Shandong Province [Grant No: ZR2016AB18] and the program of China Scholarship Council [CSC No.: 2011008046].

\section{References}

Allou, F., Chazallon, C., and Hornych, P., 2007. A numerical model for flexible pavements rut depth evolution with time. International Journal for Numerical and Analytical Methods in Geomechanics, 33, 1-22.

Alonso, E.E., Gens, A., and Josa, A., 1990. A constitutive model for partially saturated soils. Geotechnique, 40, 405-430.
Alonso, E.E., Vaunat, J., and Gens, A., 1999. Modelling the mechanical behaviour of expansive clays. Engineering Geology, 54, 173-183.

Alonso, E.E., et al., 2005. Expansive bentonite/sand mixture in cyclic controlled suction drying and wetting. Engineering Geology, 81, 213-226.

Chazallon, C., et al., 2009a. Modelling of rutting of two flexible pavements with the shakedown theory and the finite element method. Computers and Geotechnics, 36, 798-809.

Chazallon, C., et al., 2009b. Finite element modelling of the long term behaviour of a full scale flexible pavement with the shakedown theory. International Journal for Numerical and Analytical Methods in Geomechanics, 33, 45-70.

Cui, Y.J., Yahia-Aissa, M., and Delage, P., 2002. A model for the volume change behaviour of heavily compacted swelling clays. Engineering Geology, 64, 233-250.

Gens, A. and Alonso, E.E., 1992. Framework for the behaviour of unsaturated expansive clays. Canadian Geotechnical Journal, 29, 1013-1032.

Habiballah, T. and Chazallon, C., 2005. An elastoplastic model based on the shakedown concept for flexible pavements unbound granular materials. International Journal for Numerical and Analytical Methods in Geomechanics, 29, 577-596.

Moreau, J.J., 1971. "Rafle par un convexe variable", Séminaire unilatérale, Université de Montpellier, June.

Nowamooz, H. and Masrouri, F., 2008. Hydromechanical behaviour of an expansive bentonite/silt mixture in cyclic suction-controlled drying and wetting tests. Engineering Geology, 101, 154-164.

Nowamooz, H. and Masrouri, F., 2010a. Influence of suction cycles on the soil fabric of compacted swelling soil. Compted Rendus Geoscience, 342, 901-910.

Nowamooz, H. and Masrouri, F., 2010b. Mechanical behaviour of expansive soils after several drying and wetting cycles. Geomechanics and Geoengineering, 5 (4), 213221.

Nowamooz, H., Jahangir, E., and Masrouri, F., 2013. Volume change behaviour of a swelling soil compacted at different initial states. Engineering Geology, 153, 25-34.

Sharp, R. and Booker, J., 1984. Shakedown of pavements under moving surface load. Journal of Transportation Engineering, 110, 1-14.

Sun, W.J. and Sun, D.A., 2011. Coupled modelling of hydromechanical behaviour of unsaturated compacted expansive soils. International Journal for Numerical and Analytical Methods in Geomechanics, 36, 1002-1022.

Wheeler, S.J., Sharma, R.S., and Buisson, M.S.R., 2003. Coupling of hydraulic hysteresis and stress-strain behaviour in unsaturated soils. Geotechnique, 53, 41-54.

Zarka, J. and Casier, J., 1979. "Elastic plastic response of structure to cyclic loading: practical rules", Mechanics Today. Pergamon Press: Oxford, 93-198.

Zarka, J., et al. 1990. "A new approach in inelastic analysis of structures”, M.Nijhoff, Dordrecht. 